\title{
LOS "ANALES DE LA UNIVERSIDAD DE CHILE", SU NUMERACIÓN Y SUS SERIES ${ }^{1}$
}

\section{por Jorge Sanbueza}

En un oficio de fecha 14 de noviembre de 1892, leído en la sesión que en esa misma fecha celebró el Consejo de Instrucción Pública, el señor Domingo Amunátegui Solar hacía un breve comentario del "Índicealfabético y analítico de las memorias y discursos científicos y literarios publicados en los 'Anales de la Universidad de Chile' desde 1843 a 1887", cuyo autor era Eduardo Valenzuela Cueto.

A juicio de don Domingo, este índice, dedicado por el autor a don Agustín Ross, a cuya sugerencia respondió el trabajo, hubiera sido tanto mejor si en él se hubieran incluido no Sólo las memorias y discursos sino los acuerdos de cada Facultad. Entonces -dice el señor Amunáteguiel índice de los "Analesde la Universidad de Chile" (AUCH) formaría "un verdadero repertorio administrativo de instrucción pública y una bibliografía completa de los trabajos universitarios".

Esta exacta visión de la importancia de los Auch que revela la sugestión del señor Amunátegui no la tuvieron, empero en ese momento crítico en que recién se aplacaban las iras de la Revolución del '91, los demás Consejeros, que rechazaron la proposición de ir a la elaboración de un índice completo por juzgar suficiente el de Valenzuela. Amunátegui sugirió, para su aún no acogida idea, el nombre de Alejandro Aguinet.

Sin embargo, no faltaron hombres ilustres que, desde los primeros años de existencia de los AUCH, vieron en su publicación uno de los pilares de la cultura de Chile.Así, por ejemplo, en el "programa"de los AUCH, que encabeza el volumen de 1850, el primero que se publicara después del Decreto Supremo del 26 de octubre de 1849, que reglamentóla publicación, se dice -con una redacción muy semejante a la del señor Belloque la nueva forma de publicación que tendrá el periódico revelará su real valor. "El público verá en él la marcha i progreso que las ciencias i las letras hacen en Chile".

Don Ignacio Domeyko, en su cuenta sobre la marcha de la instrucción pública en Chile rendida en 1872, analiza y detalla los pormenores de los

${ }^{1}$ Este artículo fue originalmente publicado en 1963. 
aportes que a cada una de las ciencias y ramas del campode las humanidades han hecho los AUCH. Él quiere "decantar las razones porque los 'Anales de la Universidad de Chile' se hallan en el día pedidos por las academias i corporaciones científicas de varias partes del mundo i con distinción citados por los hombres mas encumbrados de la ciencia".Estos hombres se llamaban Alejandro de Humboldt, Arago, Gay, Dumoulin, Dufrénoy,Jussieu, Beaumont, entre muchos otros, y las academias solicitantes sobrepasaban en esos años las tres docenas. Para resumir, Domeyko afirma que los AUCH son los verdaderos creadores de la "literatura nacional",dando a la expresión literatura la de obra escrita cualquieraque sea su género. En 1893, al cumplirse 50 años de la fundación de la Universidad, don Diego Barros Arana afirma, en un discurso muchas veces citado y reeditado, que su contenido les ha dado "una autoridad que nosotros mismos estamos muy lejos de esperar'.

Publicadosininterrumpidamente ${ }^{2}$ desde 1846 ' hasta el presente, "Anales de la Universidad de Chile"es la mejor guía para quien desee estudiar el desarrolloy los avataresde nuestra vida intelectual. Durante la segunda mitad del siglo XIX y hasta la segunda década del presente, la idea fundamental de Andrés Bello de que la Universidad debía centrar toda su actividad en el estudio de la realidad chilena en todos sus aspectos, se deja sentir con claridad en sus páginas. Cientos de trabajos debidos a la pluma de hombres tan ilustres como Miguel Luis y DomingoAmunátegui, Francisco Astaburuaga, Diego Barros Arana, Ignacio Domeyko, Francisco Fonck, Tomás Guevara,FedericoJohow, José Victorino Lastarria, Rodolfo Lenz, Tomás Thayer Ojeda, Benjamín Vicuña Mackenna, Francisco Vidal Gormaz, Rodulfo Armando Philippi, Karl Reiche, para no citar sino a algunos, así lo comprueban. Todos los aspectos de la vida chilena, desde su historia política hasta su historia natural, desde su organizaciónjurídica y administrativa hasta su realidad geográfica y económica, sus costumbres, peculiaridades y la salud de sus habitantes, están acabadamente estudiadas en sus páginas.

El primer director con que contó la revista fue don Manuel Talavera y Garfias, secretario general interino de la Universidad, y a quien correspondió publicar los primeros cinco tomos. Lo sucedió durante un año el secretariogeneral titular, don Salvador Sanfuentes. Al año siguiente, 1850,

2En 1865 el Gobiemo resolvió no proveer de fondos a la Universidad para la publicación de la revista, pero el ConsejoUniversitarioacordóno suspenderla publicación,para lo cual proveyódinero de sus propios fondos.

3El primer tomo correspondiente a los años 1843 y 1844 se publicó en agosto de 1846. 
asumió la dirección el rector don Andrés Bello, quien corrió a cargo de la publicación, asesorado por don Ramón Briseño y por don Francisco Vargas Fontecilla, hasta 1858. Ese año es don Ramón Briseño quien toma a su cargo la publicación, hasta 1886. Durante este largo período, y gracias a la tenacidad y al celo de su director, la revista se regularizó, estabilizándose definitivamente. En 1892 es nombrado director ad-honorem don Domingo Amunátegui Solar. Más tarde, en 1921, el director es don Carlos Mondaca, prosecretario de la Universidad. Por acuerdo del Consejo del 13 de agosto de 1923, el director pasa a ser el Rector de la Universidad, a la sazón don Gregorio Amunátegui.

En 1928 se creó el cargo de Director, asumiendo esta función, por Decreto número 593 del $\mathbf{8}$ de marzo, el profesor don Franciscojorquera. En 1930 lo sucedió don Adolfo Gana Mandiola, a quien, en 1948, sucede don Eugenio Orrego Vicuña. En 1954, don Guillermo Peliú Cruz, en su calidad de secretario general de la Universidad, asume la dirección. En 1963; don Álvaro Bunster lo sucedió en este cargo, y es actualmentequien dirige la revista.

Los "Anales de la Universidad de Chile" han sufrido, como es lógico suponerlo, grandes cambios de índole formal y de contenido en el curso de sus 120 años de existencia. En 1869 se dividieron dos secciones. Se publicaron en forma paraleia hasta el año 1900, para separarse definitivamente en esta fecha. La primera de estas secciones se llamó "Analesde la Universidad de Chile: Memorias Científicas y Literarias". En ella se han publicado todas las colaboraciones de carácter científicoy literario, bajo la firma de sus autores, generalmente miembros de la Universidad o personas calificadas intelectualmente,chilenas o extranjeras. Esta sección es la que constituye propiamente los "Analesde la Universidad de Chile". La segunda sección, iniciada en $\mathbf{1 8 6 9}$ y que dejó de publicarse en $\mathbf{1 9 5 2}$, se llamó "Anales de la Universidad de Chile: Boletín del Consejo de Instrucción Pública"4, y contiene especialmente las actas de las sesiones del Consejo Universitario, los decretos y resoluciones del Rector, el movimiento administrativo de la Universidad, además de ctros numerosos documentos de alto interés para el estudio del desarrollo educacional chileno. Esta segunda sección es, en verdad, un verdadero repertorio de la instrucción pública chilena, desde el establecimiento de la Universidad hasta el año 1952.

${ }^{4}$ Acuerdo adoptado en la sesión del 27 de noviembre de 1932, que se tradujo en un nuevo reglamento para los Anales de la Universidad de Cbile. 
Desde su fundación hasta el presente los "Analesde la Universidad de Chile" se encuentran reunidos formando cuatro series. La primera serie comienza en 1846, con el tomo 1 , y termina en 1922 con el tomo cL que, por error de numeración, lleva en la portada el número clxx.

Esta serie presenta numerosas anomalías. La principal de ellas deriva del hecho de que de los $\mathbf{1 5 0}$ tomos que la componen, los $\mathbf{3 1}$ que se indican a continuación contienen exclusivamente material de la segunda sección, llamada "Boletín de Instrucción Pública". Estos tomos son: XxxuII (1870); XI (1871); XII (1872); XIIV (1873); XIVI (1874); xIVII, por error numerado xIVII (1875); ч (1876); LI (1877); LV (1878); LV (1879); LVII (1880); LX (1881); LXI (1882); LXIV (1883); LXV (1884); LXVII (1885); LXX (1886); LXXI (1887); LXXIV (1888); LXXV (1889); LXXVII (1890); LXXX (1891); LxxXII, por error numerado LXXX (1892); LXXXv (1893); ${ }^{2}$ LXXXX (1894); XCI (1895); XVv (1896); XCVI (1897); xCIX (1898); cn (1899) y cv (1900). Otras anomaiíís son las siguientes: el tomo VI, correspondiente a 1849, carece de portada; el xux, de 1876, lleva por error el número xıvin. Lo mismo sucede con los tomos LI, de 1877, que lleva el número xIXx; CXIVIn, del primer semestre de 1921, que lleva el número CLXVII; CLXXX, del segundo semestre de 1921, que lleva el número CLXIX; el ya anotado tomo cl de 1922, que lleva el número cLXX. Los tomos CXII, del primero y segundo semestre de 1917, se publicaron juntos formando un solo volumen. Con el número cxir se publicaron dos volúmenes, el del primer semestre de 1918 y el del segundo semestre del mismo año. Por último, el tomo al cual correspondí el número cxuv no se publicó, es decir, este número no fue ocupado dentro de la primera serie de $\mathbf{1 5 0}$ tomos con numeración correlativa desde el i al cL de los "Analesde la Universidad de Chile".

Fuera de estos 150 tomos, componen la primera serie de la revista dos números extraordinarios que fueron publicados en 1892 y 1911, para conmemorar el IV Centenario del Descubrimiento de América y el 1 Centenariode la Independencia de Chile, respectivamente.

La segunda serie comienza en 1923 y termina en 1930. Está formada por nueve tomos sin numeración.

La tercera serie inicia una nueva numeración, en 1931, con el número 1. Esta serie termina en 1941, comenzando al año siguientela cuarta serie,

5Llegó este título hasta 1923. Desde esta fecha hasta 1927 sellamó Boletín de Instrucción Püblica, Secundariay Superior. En 1928se llamó Boletin del Consejo Universitario. En 1933 se publicaron 3 entregas con el título de Boletin del Consejo Ejecunvo, para luego llamarse Bolerin del Consejo Universitario hasta el año en que cesósu publicación. 
que conserva la misma numeración de la tercera. Esta es la numeración que se mantiene hasta ahora.

La ficha bibliográfica de los “Anales de la Universidad de Chile", que va a leerse a continuación, ha sido preparada con el propósito de servir de guía para la formación de una colección completa de la revista. 